
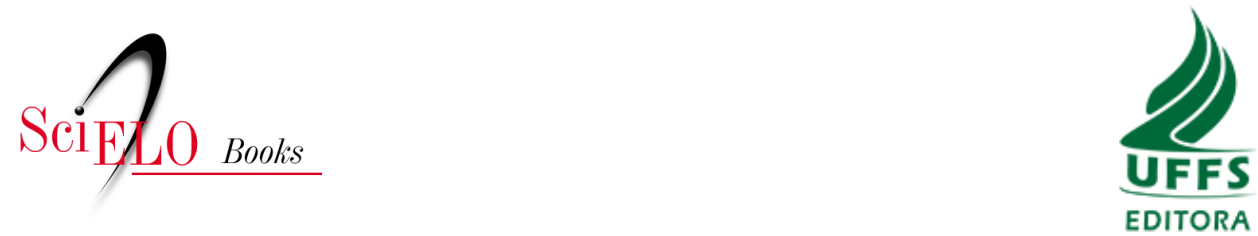

Parte I - Situando o cenário nacional e internacional e os condicionantes do modelo brasileiro

\title{
Crises financeiras: uma análise comparativa entre a bolha especulativa japonesa de 1989 e a crise dos Estados Unidos da América de 2008
}

\author{
Abel Eduardo Auth \\ Gentil Corazza \\ Lidiane Kasper
}

\section{SciELO Books / SciELO Livros / SciELO Libros}

AUTH, A.E., CORAZZA, G., and KASPER, L. Crises financeiras: uma análise comparativa entre a bolha especulativa japonesa de 1989 e a crise dos Estados Unidos da América de 2008. In: ROTTA, E., LOPES, H. C., and ROSSINI, N., eds. O modelo de desenvolvimento brasileiro das primeiras décadas do século XXI: aportes para o debate [online]. Chapecó: Editora UFFS, 2018, pp. 183-207. ISBN: 978-85-64905-82-5. https://doi.org/10.7476/9788564905832.0008.

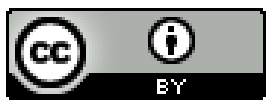

All the contents of this work, except where otherwise noted, is licensed under a Creative Commons Attribution 4.0 International license.

Todo o conteúdo deste trabalho, exceto quando houver ressalva, é publicado sob a licença Creative Commons Atribição 4.0.

Todo el contenido de esta obra, excepto donde se indique lo contrario, está bajo licencia de la licencia Creative Commons Reconocimento 4.0. 


\title{
CRISES FINANCEIRAS: UMA ANÁLISE COMPARATIVA ENTRE A BOLHA ESPECULATIVA JAPONESA DE 1989 E A CRISE DOS ESTADOS UNIDOS DA AMÉRICA DE 2008
}

\author{
Abel Eduardo Auth \\ Gentil Corazza \\ Lidiane Kasper
}

\section{INTRODUÇÃO}

O principal objetivo deste texto é analisar duas grandes crises financeiras, uma ocorrida no Japão, em 1989, e outra nos Estados Unidos, em 2008, no contexto das transformações do sistema financeiro global. Seus objetivos específicos procuram apontar as principais características do sistema financeiro e as causas dessas crises, destacando suas semelhanças e suas diferenças, bem como suas consequências para a economia mundial e, de modo especial, para a economia brasileira.

Para analisar essas duas crises localizadas, faz-se necessário situá-las no contexto mais geral da economia e especialmente do sistema financeiro mundial. Nesse sentido, observa-se que,desde a consolidação do sistema financeiro globalizado contemporâneo, que ocorreu ao longo da década de 1980, foram registrados pelo menos cinco eventos importantes, que estão relacionados a bolhas financeiras (TORRES FILHO, 2014). O mesmo autor destaca haver evidências no sentido deque a "maneira como os 
sistemas financeiros passaram a operar a partir da segunda metade da década de 1980 acelerou a formação de bolhas especulativas financeiras de grande porte" (TORRES FILHO, 2015, p. 10). O que ele quer dizer é que, a partir de meados dos anos 1980, o sistema financeiro mundial passou por um acentuado processo de globalização e de liberalização e que essa maneira de operar de forma mais livre e integrada aumentou seu potencial de instabilidade e de provocar crises, tanto em nível nacional como em nível mundial.

Nesta relação de bolhas especulativas financeiras, que podem originar-se no mercado imobiliário ou no mercado de ações, podem ser incluídos os eventos ocorridos no Japão e também nos países escandinavos, na segunda metade de 1980, na Ásia (1992 e 1997), no México (no início dos anos 1990) e no mercado americano de ações, crise que ficou conhecida por "bolha da internet", de 2000/2001 (TORRES FILHO, 2015, p. 10). O autor ainda complementa que "certamente, a crise de 2008 teria sido incluída por Kindleberger e Aliber em sua lista caso o livro não tivesse sido finalizado antes". Diante desses fatos, o autor chama a atenção para duas bolhas especulativas, consideradas por ele como as mais marcantes, que se desenvolveram a partir dos anos 1980, sendo elas a bolha especulativa Japonesa de 1989 e a dos Estados Unidos de 2008.

A bolha especulativa japonesa de 1989 está relacionada ao mercado de ações e de imóveis e ficou conhecida por ser um episódio importante no último quarto do século XX, bem como pelo seu impacto econômico e financeiro gerado na economia japonesa (TORRES FILHO, 2015). Uma das características do caso da bolha especulativa japonesa, segundo o autor, é que seus efeitos ficaram basicamente condicionados à economia local, mas seus impactos foram tão fortes, que mesmo com a atuação do governo para conter seus efeitos, o país até hoje não conseguiu recuperar-se inteiramente daquela crise.

Por outro lado, a crise de 2008, nos Estados Unidos, levou a uma prolongada e profunda crise na economia mundial, ou seja, seus efeitos foram 
disseminados para o resto do mundo, sendo que algumas economias foram afetadas diretamente, em razão das perdas decorrentes do mercado hipotecário americano, ao passo que outras foram afetadas indiretamente, como no caso da economia brasileira (MUNHOZ, 2009).

Assim, para atingir os objetivos propostos de analisar o problema da bolha especulativa japonesa de 1989 e a crise dos Estados Unidos de 2008, adota-se, neste estudo, a metodologia da pesquisa bibliográfica, considerando que este tipo de pesquisa é desenvolvido a partir de materiais já elaborados, como livros e artigos científicos (GIL, 2002). Nesse sentido, este capítulo foi elaborado tendo como base principal os estudos de Ernani Teixeira Torres Filho, professor do Instituto de Economia da Universidade Federal do Rio de Janeiro (UFRJ), além de textos de outros autores, que abordam o mesmo tema aqui proposto.

Para tanto, após esta Introdução, o texto está estruturado nos seguintes tópicos: características do sistema financeiro globalizado contemporâneo, o caso japonês de 1989, o caso dos Estados Unidos de 2008 e reflexos no Brasil. Nas considerações finais, procurar-se-á destacar as principais questões analisadas ao longo do trabalho.

\section{O SISTEMA FINANCEIRO GLOBALIZADO CONTEMPORÂNEO}

Para compreender as principais características do sistema financeiro globalizado atual, sua natureza, seu funcionamento e as consequências para a produção da economia, faz-se necessário resgatar a estrutura e as características do sistema financeiro mundial, logo após a Segunda Guerra Mundial. Há diferenças importantes entre o sistema financeiro organizado logo após a Segunda Guerra e o sistema financeiro globalizado, que se estruturou no final da década de 1970 e no decorrer da década de 1980. Logo após a Segunda Guerra, o sistema financeiro começou a ser regulado 
pelos princípios e regras do chamado Acordo de Bretton-Woods. Nos anos 1970-80, o sistema financeiro tornou-se liberalizado e globalizado, de acordo com o espírito do chamado Consenso de Washington, o qual, segundo Torres Filho (2015a, p. 10), "somente se tornou plenamente funcional a partir da segunda metade da década de 1980". Entre um e outro período, o sistema financeiro mundial passou por profundas transformações de caráter liberalizantes.

Assim, em relação ao Acordo de Bretton-Woods, Baer et al. (1995, p. 81-82) destacam:

[...] o Acordo de Bretton-Woods, portanto, foi importante como procedimento de institucionalização da hegemonia dos EUA no campo monetário internacional, e o aspecto-chave neste sentido foi a definição do ouro como ativo de reserva. A partir da aceitação do dólar como referencial internacional, a gestão monetário-financeira mundial, de fato, passa a estar sujeita aos ditames da política norte-americana.

Para tanto, no período posterior à Segunda Guerra Mundial, o Sistema Financeiro de Bretton-Woods era um sistema regulado, que se apoiava na hegemonia dos Estados Unidos com o dólar lastreado em ouro, e nas taxas de câmbio fixas, mas com algum grau de flexibilidade, sob autorização do Fundo Monetário Internacional (FMI). Nos termos de Baer et al. (1995, p. 81),

[...] cabia ao FMI, em primeiro lugar, zelar pelo cumprimento das regras cambiais, inclusive coordenando as revisões das estruturas de paridade quando se tornassem necessárias. Em segundo lugar, com a disponibilidade de recursos financeiros mínimos que lhe seriam postos à disposição pelos países membros, o Fundo deveria estender os financiamentos compensatórios e, simultaneamente, supervisionar as "correções" nas políticas macroeconômicas dos países que apresentassem deficit (transitórios) em seus balanços de pagamentos. 
Além do FMI, que devia atuar como regulador das relações monetárias, financeiras e cambiais entre os países, foram criados outros organismos reguladores e financiadores das atividades econômicas internacionais, como a Agência Geral de Comércio e Tarifas (GATT) e o Banco Internacional para a Reconstrução e o Desenvolvimento (BIRD), também conhecido como Banco Mundial, cujo objetivo "era atuar na reconstrução da Europa para garantir a ordem monetária internacional. No entanto, desde o princípio, o papel desta segunda instituição era totalmente secundário" (BAER et al.,1995, p. 81).

Finalmente, todas essas instituições e demais regras do Acordo de Bretton-Woods exerciam um razoável controle sobre os movimentos internacionais de capitais. Este sistema financeiro internacional conferiu grande estabilidade monetária e propiciou um período de grande crescimento econômico internacional, do qual o Japão foi um dos principais expoentes, com elevadas taxas de crescimento, conforme se verificará logo a seguir.

Como menciona Torres Filho (2015a, p. 10-11), o sistema financeiro que resultou do Acordo de Bretton-Woods se apoiava nas seguintes regras: i) taxas fixas de câmbio, mas ajustáveis, com autorização do FMI; ii) garantia de conversibilidade dos saldos de dólares em ouro, com taxas fixas de câmbio; iii) ampla conversibilidade das operações financeiras de origem comercial; iv) controle das contas de capital pelos governos nacionais. Esse conjunto de regras, com destaque para as taxas fixas de câmbio e o controle sobre movimentos de capitais, conferiam uma grande estabilidade ao sistema financeiro internacional, estabilidade que foi comprovada pela ausência quase completa de crises financeiras no período da vigência deste sistema financeiro, entre 1947 e 1973. A outra virtude desse sistema financeiro regulado foi o grande crescimento econômico mundial que proporcionou.

Mas esse sistema começou a entrar em crise, no início dos anos 1970, com a quebra da conversibilidade do dólar em ouro (o valor do dólar deixou de valer determinada quantidade de ouro), ficando completamente 
variável seu valor, de acordo com as estimativas do mercado. Dathein (2005, p. 57) explica:

[...] em 1970 e 1971, o fluxo de dólares ao exterior multiplicou-se, gerando maior instabilidade, e, em agosto de 1971, as reservas dos EUA caíram abaixo do nível psicologicamente crítico de US\$10 bilhões. Neste momento, Nixon anunciou uma série de medidas, entre elas a suspensão da conversibilidade do dólar em ouro. Logo após, foi negociada (Acordo Smithsoniano) uma desvalorização do dólar, e a faixa de flutuação cambial admitida foi ampliada de $1 \%$ para 2,25\%. As tentativas de manter as taxas de câmbio fixas duraram até 1973, quando o sistema acordado em Bretton Woods soçobrou completamente. A partir deste momento, as taxas passaram a flutuar conforme o mercado e as decisões dos governos. Os membros da CEE ainda tentaram manter entre si uma margem de variação cambial admissível, que foi chamada de "serpente do túnel", com êxito parcial por algum tempo.

Começava ali a grande transformação do Sistema Financeiro Internacional: "desde a crise do padrão monetário estabelecido em Bretton-Woods, ocorreram profundas alterações no funcionamento do sistema financeiro internacional" (BAER et al., 1995, p. 86), passando de um sistema financeiro regulado para um sistema globalizado e liberalizado. Sua principal característica é a instabilidade intrínseca e sua propensão a gerar crises financeiras. Nesse sentido, Torres (2015a, p. 10) destaca que "a maneira como os sistemas financeiros passaram a operar, a partir de 1985, tendeu a provocar mais bolhas especulativas financeiras de grande porte que a experiência histórica anterior”. Já Dathein (2005, p. 59) complementa que:

[...] desde o colapso de Bretton-Woods, o sistema financeiro privado internacional apresentou profundas alterações. Fatores microeconômicos, como as inovações tecnológicas e as mudanças de padrões de concorrência, ajudaram a viabilizá-las. Fatores macroeconômicos, por outro lado, podem ser entendidos como indutores das transformações. Estes fatores macroeconômicos podem ser relacionados à instabilidade e aos desajustes econômicos internacionais. 
Cabe destacar aqui a diferença fundamental entre a construção do sistema financeiro de Bretton-Woods e o sistema financeiro globalizado contemporâneo, que resultou de uma progressiva liberalização financeira sob a pressão dos interesses dominantes do mercado. Conforme lembra Torres Filho (2015b, p. 01) "a montagem do sistema financeiro globalizado contemporâneo não seguiu um roteiro preestabelecido, como ocorreu no Acordo de Bretton-Woods. Foi sendo feita aos poucos e de forma pragmática, ao sabor das pressões e contrapressões dos principais atores".

Ainda, de acordo com Torres Filho (2015b, p. 01), a "liberalização financeira levou os bancos e as demais instituições financeiras internacionais a uma concorrência aberta, gerando níveis de alavancagem e de crédito recordes". Ao mesmo tempo em que bancos e instituições financeiras passaram a concorrer em nível global, sem restrições, "os controles nacionais dos fluxos internacionais de capitais foram sendo paulatinamente substituídos por um mecanismo regulatório global inteiramente novo" (TORRES FILHO, 2015b, p. 01), sob controle dos grandes agentes financeiros internacionais.

Além do caráter privado dos grandes agentes do sistema financeiro globalizado e desregulado, cabe acrescentar a liberalização financeira, que permite a livre mobilidade de imensas quantidades de capitais especulativos, no mercado internacional, favorecidos por taxas de câmbio flutuantes, o que permite a esses capitais usufruírem ganhos extraordinários, onde quer que eles existam. É justamente este caráter desregulado e liberalizado do sistema financeiro globalizado, associado a uma massa de riqueza financeira sem precedentes, sem controle dos seus fluxos internacionais, com taxas de câmbio flutuante, que provoca a instabilidade financeira e as crises internacionais, como as do Japão e dos Estados Unidos, que serão analisadas nos tópicos a seguir.

Em síntese, destacam-se as principais características do sistema financeiro globalizado contemporâneo: i) em contraste com o sistema financeiro de Bretton-Woods, que resultou de um acordo internacional, o 
atual sistema financeiro foi construído aos poucos, a partir das práticas do mercado financeiro; ii) taxas flexíveis de câmbio entre moedas; iii) livre movimentação de capitais; iv) fim da conversibilidade dólar-ouro. Ao contrário do que se passava com o sistema financeiro anterior, o sistema financeiro globalizado e liberalizado contemporâneo é mais propenso a gerar crises financeiras.

\section{O CASO JAPONÊS DE 1989}

Após a destruição do Japão na Segunda Guerra Mundial, o país ficou sob comando econômico e militar das forças americanas por um longo período, considerando que o esforço de guerra havia deixado sua indústria em situação de esgotamento, e que resultou na escassez de fontes de matérias-primas e alimentos, além de um elevado desemprego e altas taxas de inflação (TORRES FILHO, 1997; PORTINHO, 2009). Como ressalta Torres Filho (1997), face ao estado de crise e destruição em que se encontrava o Japão logo após a Segunda Guerra Mundial, parecia difícil imaginar a sua reestruturação, como veio a ocorrer nos anos seguintes.

Diante da situação em que se encontrava o país desde o fim da Segunda Guerra Mundial, Portinho (2009) destaca que "o direcionamento de capitais destinados à reconstrução do Japão e a proteção militar oferecida pelos americanos permitiram um rápido crescimento da capacidade produtiva do Japão". Nesse período o paístambém retoma o incentivo à poupança entre sua população; tal medida logo se dissemina entre a população e partes dos rendimentos familiares passam a ser guardados em bancos (ALVES, 2012). O autor complementa que, com a alta taxa de poupança interna do país, os bancos passaram a investir na reconstrução da economia japonesa, sendo que suas indústrias também voltaram a funcionar com o auxílio destes financiamentos. 
Assim, segundo Alves (2012), ao longo dos anos o país começa a dar sinais de recuperação, grande parte em razão de sua economia exportadora de produtos com alto valor agregado, em sua maioria industriais, aliados aos investimentos em educação e qualificação de mão de obra. Ainda segundo o autor, com a ameaça do comunismo na Ásia, o Japão se torna parceiro dos Estados Unidos da América (EUA), o que contribui para receber investimentos norte-americanos, além de abrir portas para a venda de seus produtos industriais no mercado dos EUA.

Passados quarenta anos da derrota do Japão na Segunda Guerra Mundial, o país apresentava uma situação econômica e social completamente diferente do cenário do pós-guerra (TORRES FILHO, 1997). O saldo de poupança interna do país, ao lado dos investimentos em educação, qualificação de mão de obra e os investimentos dos EUA são fatores que contribuíram para o Japão atingir, entre 1953 a 1973, um crescimento de 9,4\% a.a. (ALVES, 2012). Durante o mesmo período, o PIB dos EUA apresentava um crescimento anual de apenas 3,6\%, o Reino Unido, 3,1\%, a Alemanha Ocidental, 5,8\% e a França, 5,3\%. Esse extraordinário crescimento econômico ficou conhecido como o "milagre econômico" japonês, uma vez que representava um crescimento recorde do Japão, quando comparado às economias mais desenvolvidas (TORRES FILHO, 1997).

O crescimento que a economia japonesa vinha apresentando foi afetado pelo Choque do Petróleo de 1973, fazendo com que o Banco Central japonês adotasse uma medida de diminuição das taxas de juros com o objetivo de continuar estimulando a economia, e sua população seguiu poupando apesar da taxa de juros menor (ALVES, 2012). Mesmo com desaceleração proveniente da Crise do Petróleo, o país conseguiu crescer $4 \%$ ao ano, durante o período de 1974 a 1982, nível não atingido pelos demais países ricos, sendo que os EUA, neste mesmo período, cresceram 1,5\%, Reino Unido 1,0\%, Alemanha Ocidental 1,6\% e a França 2,4\% (TORRES FILHO, 1997). 
Em 1980, os EUA adotaram uma política de elevação da taxa de juros, ao mesmo tempo em que também ocorreu uma valorização cambial da moeda norte-americana em comparação a de seus parceiros comerciais, sendo que entre 1971 e 1980 o dólar desvalorizou cerca de 25\%, quando comparado a outras moedas, porém em 1985 a moeda chegou a valer $80 \%$ mais do que valia em 1980 (TORRES FILHO, 1997). O autor complementa que todas essas variações cambiais que passaram a ocorrer tenderiam a afetar negativamente a competitividade das empresas americanas tanto no mercado interno como no externo.

Nesse contexto, o Japão foi o principal favorecido com os deficit norte-americanos, considerando-se que, em 1980, as exportações dos EUA tiveram uma estagnação, ao passo que as importações aumentaram cerca de 50\%, atingindo um deficit de US\$ 170 bilhões, em 1987 (TORRES FILHO, 1997). O autor destaca ainda que o bom desempenho da economia japonesa, aliado ao crescente superavit comercial com os EUA e uma certa dependência deste país de financiamentos de longo prazo de capitais japoneses, indicava que o Japão estava ameaçando o poder hegemônico dos EUA, na segunda metade dos anos 80 .

Segundo Alves (2012), como nos anos 1980 a renda per capita no Japão era alta, muitas pessoas, especialmente da classe alta e média, começaram a gastar mais dinheiro. Os mais ricos compravam obras de arte no exterior, construíam prédios e torres, enquanto que a classe média abusava no consumo, embora ainda seguisse poupando. Já Fraga e Strachman (2013) mencionam que o crescimento econômico japonês, que se estendeu até meados da década de 1980, também foi acompanhado por um aumento do preço das terras, imóveis e das ações, que "contribuiu para o enriquecimento das famílias japonesas que possuíam moeda, depósitos bancários, imóveis e ações" (KINDLEBERGER; ALIBER, 2009, p. 175).

Ademais, o aumento das importações de produtos japoneses, feitas pelos EUA, a partir de 1981, resultou em superavit para os japoneses e também fez com que o iene se valorizasse frente ao dólar (ALVES, 2012). 
Naquele momento, grande parte dos dólares em circulação na economia convertiam-se em ativos japoneses, interferindo na economia local, fato que forçou o governo japonês a adotar medidas a fim de evitar uma nova valorização da sua moeda e gerar um descontrole na política monetária, entretanto essa estratégia também dependia da participação do setor privado (TORRES FILHO, 2015). Alves (2012, n.p.) complementa que “[...] o governo japonês, para aumentar suas exportações, manipulava o câmbio, desvalorizando a sua moeda, o que era tido como concorrência desleal [...]" por parte de outros países, especialmente os EUA.

Os Estados Unidos, diante da manutenção de elevados deficit com o Japão, entram com uma nova ofensiva, em 1985, com a qual buscavam mudar a taxa de câmbio entre as duas moedas. Para atingir esse objetivo, americanos, europeus e japoneses passaram a realizar intensas negociações, que se materializaram no Acordo do Plaza (TORRES FILHO, 2015). De acordo com Tavares (1996), através do Acordo do Plaza deveria ocorrer uma valorização do iene em relação ao dólar. Nesse sentido, o Japão esperava que o iene se valorizasse de 240 unidades por dólar para 160 a 170 unidades. A partir de 1987, contudo, o iene passou a ser trocado na proporção de 130 ienes por dólar, resultando num choque cambial de valorização, que ficou conhecido por "endaka" ou "iene forte" (TORRES FILHO, 2015).

Tal política, segundo Tavares (1996), acabou provocando uma redução na taxa de crescimento da economia japonesa e também nos lucros dos setores exportadores e, como forma de compensar os prejuízos, o governo decidiu, por meio de uma política monetária expansionista, aumentar a demanda interna. Assim, de acordo com Torres Filho (2015, p. 12), “a taxa de redesconto, que estava em 5\% a.a., no início de 1986, foi sendo reduzida até alcançar 2,5\% a.a., em fevereiro de 1987, o menorvalor registrado até então". Levi (1997) explica que os empréstimos e as taxas de redesconto do Banco do Japão eram os principais instrumentos de política monetária adotada pelo país. 
O objetivo de tal política era estimular novamente a demanda interna, a fim de compensar as perdas provocadas pela redução das exportações, o que de fato contribuiu novamente para o crescimento do consumo privado e também para o investimento, principalmente voltados a moradias (TORRES FILHO, 2015). Uma maior circulação de dinheiro no país e os juros mais baixos serviram de estímulo para que as empresas captassem mais empréstimos, sendo que os bancos emprestavam até $70 \%$ do valor avaliado dos imóveis dados em garantia, o que também contribuiu para que ocorresse uma valorização imobiliária (ALVES, 2012; KINDLEBERGER; ALIBER, 2009).

Com o aumento do crédito, muitos investidores, diante do cenário de valorização de imóveis e ações, passaram a especular e conseguir dinheiro fácil nos bancos a fim de aumentar sua lucratividade e seus ganhos através dessas especulações (ALVES, 2012). Ainda segundo o autor, as exportações aos poucos foram retomando o crescimento, considerando que o iene desvalorizava frente a moeda norte-americana, fato que obrigava o Banco Central japonês a adotar uma nova estratégia, ou seja, aumentar sua taxa de redesconto ainda mais. Torres Filho (2015, p. 13), contudo, complementa que "esse capital adicional aumentava a capacidade de endividamento das empresas e das famílias junto ao setor bancário”.

Segundo Torres Filho (2015, p. 14), “em 1988, a economia japonesa já dava sinais de ter superado o quadro recessivo decorrente do endaka. Tudo indicava que o setor privado japonês estava dando partida a um novo ciclo de crescimento, centrado na demanda interna”. Porém, a situação não parecia tão simples, uma vez que, no início de 1989,o Banco Central japonês decide adotar uma política restritiva de crédito, momento em que "ataxa de desconto foi continuamente aumentada, saindo de um mínimo de $2,5 \%$, no primeiro trimestre de 1989 , até atingir $6 \%$, no terceiro trimestre de 1990" (TORRES FILHO, 2015, p. 14).

Diante desse contexto, como não ocorria uma resposta à nova política monetária,em 1990, o Ministério das Finanças do Japão limita aos bancos 
o valor dos empréstimos para as empresas e imobiliárias, resultando em uma diminuição dos preços dos imóveis (ALVES, 2012; TORRES FILHO, 2015). Diante disso, como destaca Alves (2012), os japoneses passam a limitar seu consumo, aliado à ocorrência de uma redução nas suas exportações, em razão de uma maior competição nas exportações de produtos tecnológicos. Assim, na década de 1990, o país passou a ter uma baixa taxa de crescimento econômico em comparação com os principais países industrializados, estagnação e declínio nos preços das ações, das terras e imóveis (FRAGA; STRACHMAN, 2013).

Além disso, diante de um conjunto complexo de interações de diferentes fatores é que se originou a bolha especulativa japonesa, entre os quais é possível mencionar a desregulamentação do sistema financeiro, da década de 1980, o Acordo do Plaza, de 1985, e a própria condução da política monetária (FRAGA; STRACHMAN, 2013). "O estouro da 'bolha' transformou-se em um pesadelo", conforme Torres Filho (2015, p.14), pois, com a desvalorização dos imóveis e das ações, as falências aumentaram, considerando-se que as empresas e famílias especuladoras nesse mercado começaram a ter prejuízos, uma vez que as garantias dadas pelos empréstimos perderam valor. Além disso, os bancos e outras instituições financeiras também passaram a ter grandes perdas (KINDLEBERGER; ALIBER, 2009; TORRES FILHO, 2015). Segundo Kindleberger e Aliber (2009, p. 176), "as ações caíram 30\% em 1990 e outros 30\% em 1991. A tendência desses preços no Japão despencou apesar de quatro significativas retomadas".

Segundo Torres Filho (2015), a partir da crise financeira do Japão de 1989 a economia do país passou por um processo de desaceleração, que mais tarde se transformou em um processo de estagnação, ficando a taxa média de crescimento, na segunda metade da década de 1990, segundo Fraga e Strachman (2013), próxima de 1\% apenas.

Ademais, nesse período a taxa de desemprego aumentou, atingindo um nível de 5\%, o que era considerado elevado para o padrão japonês, ao 
passo que a inflação, entre 1991 e 2006, caia de 3,5\% para praticamente zero, negativa ou nula (INTERNATIONAL MONETARY FUND, 2011 apud FRAGA; STRACHMAN, 2013).

Torres Filho (2015) ainda menciona que esse fenômeno foi marcado por um processo de desalavancagem financeira das empresas que perdurou por muito tempo, mesmo o país adotando taxas próximas a zero. $\mathrm{O}$ autor ainda explica que, devido às consequências vividas com o estouro da bolha especulativa de 1989, as empresas, mesmo tendo saldos positivos e com acesso a empréstimos bancários a taxas de juros baixos, preferiam pagar suas dívidas e acabavam por não realizar novos investimentos, enquanto que as famílias trouxeram para próximo de zero o superavit que vinham acumulando, em razão das perdas de empregos e salários.

Desde o estouro da bolha, de acordo com Barros (2013, p. 194),

[...] o cenário deflacionário impera no país, com todos os problemas decorrentes desta situação, como retração no consumo e no investimento. Uma queda recorrente no tamanho da população, seu envelhecimento (com o conseqüente déficit estrutural da previdência) e a resistência social à imigração só complicam o quadro [...].

O longo período de estagnação vivenciado pelo Japão é explicado por Fraga e Strachman (2013) em razão da morosidade na atuação fiscal por parte do governo, acentuada pela sua má condução, quando adotada, além da condução dada à política monetária e demora na adoção de políticas “orientadas” para o setor bancário.

\section{O CASO DOS ESTADOS UNIDOS DE 2008}

Nos Estados Unidos, os investimentos financeiros nos anos $2000 \mathrm{mi}$ graram fortemente dos setores da informática e dos serviços de informação para setores imobiliários e de construção civil, em função do estouro da bolha especulativa da internet. Os investidores passaram a considerar os 
ramos imobiliários como setores "reais", o que gerou um enorme fluxo de capital financeiro. No decorrer do estouro da bolha especulativa da internet, o governo criou políticas anticíclicas reduzindo as taxas de juros de 6,4\% para $1,8 \%$, amortizando a crise e realocando portfólios de investimento no país para os setores de habitação familiar (TORRES FILHO, 2015). O governo implementou políticas de liberação de crédito para famílias e pessoas que não necessariamente possuíssem fama de "bons pagadores": "O governo Clinton, incluindo aí os democratas na Câmara e no Senado, estabeleceu regras e usou sua influência para estimular as agências a afrouxar os critérios para a concessão de empréstimos, de modo a ampliar o universo de famílias beneficiadas" (LEAL, 2012, n.p.).

Os bancos de investimento de Wall Street, segundo Leal (2012), ao perceberem o crescimento de mais de $50 \%$ do mercado de venda de casas e imóveis, desenvolveram uma forma de repassar o alto risco desses créditos de financiamento a investidores que almejassem altos retornos. "O dinheiro farto fez os preços dos imóveis irem para as alturas, alimentando a bolha especulativa" (LEAL, 2012, n.p.). Inicia-se, então, uma nova bolha especulativa de investimentos nos EUA, a dos títulos de imóveis residenciais de alto risco.

A oferta de financiamentos para o setor imobiliário, segundo Torres Filho (2015), era tamanha que as famílias que não possuíam liberação de crédito em épocas anteriores, por fatores como desemprego, falta de patrimônio para oferecer em hipoteca ou histórico de inadimplência em financiamentos anteriores, passaram a conseguir liberação para adquirir um imóvel de forma ágil pela grande oferta de crédito disponível. Torres e Borça (2009) esclarecem:

A maior parte delas não tinha condições de arcar nem com o sinal nem com o pagamento de seu financiamento no médio prazo, a menos que o valor do imóvel adquirido subisse mais que o custo corrente do financiamento e a hipoteca fosse renegociada (apud TORRES FILHO, 2015, p. 19). 
Os devedores do tipo Subprime, de acordo com Sousa (2011), são aqueles que não possuíam crédito para bancar seus financiamentos de imóveis e que, com a crescente valorização das propriedades, passaram a renegociar suas hipotecas, com um preço de imóvel superior àquele de quando efetivado o financiamento, gerando consequentemente calotes nos seus credores. "A recente crise financeira que teve início no mercado imobiliário norte-americano em 2007 - a partir da securitização dos empréstimos concedidos para devedores do tipo Subprime - derrubou a economia global" (SOUSA, 2011, p. 9).

A crise de 2008 nos EUA proveniente do estouro da bolha especulativa de investimentos imobiliários, conforme Carvalho (2010), acabou se transformando em uma crise financeira de grande proporção, não apenas para o mercado norte-americano, mas também para todos os países desenvolvidos e subdesenvolvidos inseridos na sua escala financeira, os quais entraram em recessão com os EUA. Carvalho (2010) atenta para as taxas de juros que eram pós-fixadas nos financiamentos dos imóveis e se tornaram elevadas, promovendo altos índices de inadimplência entre os devedores, os quais foram responsáveis por levar os bancos comerciais à falência desencadeando um efeito cascata em todas as entidades comerciais envolvidas no processo.

A falência da Lehman Brothers (importante instituição financeira americana), segundo Torres Filho (2015), foi o estopim da crise norte-americana de 2008, quando todo o sistema financeiro travou e entrou em busca desenfreada por liquidez. Os preços dos imóveis despencaram e toda a economia entrou em profunda recessão. "A partir daí foi uma sucessão de quase falências (AIG, General Motors, Chrysler, Bank of America, Citigroup, [...]) que só foram evitadas com forte intervenção do Estado e do Federal Reserve, Banco Central dos EUA. No entanto, já havia sido conflagrada a crise." (BASTOS; TEIXEIRA, 2015, p. 03).

A crise configurou-se no país, desencadeando reações: 
Como resultado, os preços dos ativos despencaram e o crédito desapareceu, arrastando consigo para baixo o nível de atividade. $\mathrm{O}$ mercado de derivativos também ficou sem rumo, na medida em que perdeu um de seus principais veículos de contraparte, o próprio Lehman Brothers (TORRES FILHO, 2015, p. 20).

O principal efeito na economia norte-americana, conforme Sousa (2011), foi o corte de crédito pessoal por parte dos bancos, que vinha alimentando a compra de bens de consumo, agravando a recessão econômica. Para Carvalho (2010), o governo foi forçado a conceder redução de impostos para a classe média e obrigado a promover incentivos fiscais para as pequenas empresas como política anticíclica à crise.

O governo norte-americano, ao deparar-se com a profunda recessão, aplicou políticas anticíclicas voltadas ao crescimento e conseguiu reduzir a inflação de 5,2\% a.a. no final de 2008 para 2\% a.a. no final de 2009 (TORRES FILHO, 2015). A recuperação também se iniciou nos países periféricos: “Após o segundo semestre de 2009, alguns países já começaram a dar os primeiros sinais de recuperação. Estes sinais, contudo, foram mais expressivos nas economias emergentes" (SOUSA, 2011, p. 09). A alteração macroestrutural também foi visível no contexto mercadológico americano, e as empresas passaram a gerar mais lucro e investir menos no país, acumulando capital como forma de promover poupança forçada (TORRES FILHO, 2015).

A política de distribuição de renda que estava presente na economia americana desde meados da Segunda Guerra Mundial sofreu um processo de inflexão, e o foco passou a ser acumulação de capital, lucro e investimentos valorizando empresas em detrimento do crédito familiar e de consumo. As diferenças entre a crise americana e a crise japonesa: no Japão houve maior participação direta de pessoas físicas na economia, e a contração da demanda de serviço nas empresas americanas também foi menor que nas empresas do Japão (TORRES FILHO, 2015). O autor complementa que, nos EUA, diferentemente do Japão, a quebra do setor 
privado foi coberta pelo aumento do deficit dos cofres públicos nacionais, assim como a crise como um todo teve duração cronológica menor. E acrescenta, ainda, que as empresas americanas também tiveram mais amparo estatal e estavam menos fragilizadas, adquirindo menor endividamento que as empresas japonesas.

A crise americana de 2008 foi mais um paradigma mundial a demonstrar que o Estado precisa ter maior intervenção junto ao mercado e atuar como agente regulador com caráter keynesiano: "O risco construído poderia ter sido evitado se as políticas financeiras fossem guiadas pelo senso pragmático, sugerido por Keynes, e não pela ideologia fundamentalista da crença na eficiência do mercado" (CARVALHO, 2010, p. 11).

\section{REFLEXOS DA CRISE NORTE-AMERICANA NO BRASIL}

A primeira observação a ser feita é que, dado o alto grau de integração das economias nacionais na economia internacional, é muito difícil, para não dizer impossível, que uma crise como a que ocorreu nos EUA, em 2008, deixe de afetar uma economia como a brasileira. O impacto, maior ou menor, da crise americana e internacional sobre a economia brasileira depende de uma série de fatores, como o grau de abertura econômica, comercial e financeira, o tipo de inserção mais autônoma ou mais subordinada da economia brasileira na economia mundial e, finalmente, das medidas de política econômica interna tomadas para amenizar os impactos da crise.

A crise mundial de 2008, que se originou nos EUA, ocorreu durante o segundo mandato do presidente Lula. Ela afetou a economia brasileira em vários pontos (MARQUES; ANDRADE, 2015). O primeiro deles foi através da forte queda dos preços internacionais das commodities, acarretando grandes perdas do comércio internacional do país. O segundo efeito da crise sobre a economia brasileira foi a retração da demanda 
internacional por produtos brasileiros, com consequências negativas também sobre o comércio internacional do Brasil. O terceiro efeito negativo da crise sobre a economia brasileira foi a queda acentuada da entrada de capitais estrangeiros no país. Os primeiros dois efeitos da crise afetaram a economia brasileira pelo lado da demanda de seus produtos de exportação, os quais, além de prejudicar o balanço de pagamentos, pela queda das exportações, acabaram também por afetar tanto a produção interna como o nível de emprego. O terceiro fator, relativo à queda da entrada dos capitais estrangeiros, afetaram negativamente o nível dos investimentos internos, causando também a queda do produto interno.

$\mathrm{O}$ efeito conjunto desses fatores externos representaram uma diminuição do crédito interno da economia, uma queda da demanda interna e uma redução do ritmo de atividades e aumento do desemprego (MARQUES; ANDRADE, 2015).

A resposta do governo brasileiro aos efeitos da crise não se fez esperar e veio através de uma série de medidas anticíclicas de estímulo às atividades internas. A primeira delas foi estimular o crédito bancário, especialmente através dos bancos públicos, como o BNDES, o Banco do Brasil e a Caixa Econômica Federal. A expectativa do governo era que os demais bancos privados seguissem os bancos públicos, mas isto só ocorreu em parte e por curto período. Ao mesmo tempo em que o governo federal estimulava o crédito bancário, tomava medidas de fortalecimento dos bancos menores e mais frágeis, com vistas a evitar uma crise bancária, como havia acontecido nos EUA e na União Europeia. Outra medida tomada pelo governo, no sentido de estimular a economia, foi reduzir os impostos de uma série de produtos industriais, bem como do imposto de renda das pessoas físicas. Por último, foram tomadas medidas para amenizar os problemas do desemprego, através do estímulo ao seguro-desemprego.

Quais foram os efeitos dessas medidas tomadas pelo governo brasileiro? À primeira vista, pode-se dizer que seus resultados foram fracos, pois a economia nacional teve uma queda de $0,2 \%$ no PIB, devido à queda do 
produto industrial de 5,6\% e do agropecuário com queda de 3,1\%; as exportações, por sua vez, diminuíram em 9,1\% (IPEADATA, 2016). Como avaliar esses dados? Do ponto de vista teórico, é possível dizer que as medidas de política econômica tomadas foram corretas, porém seus efeitos parecem ter sido fracos. Talvez pudessem ter sido mais arrojadas. No entanto, cabe perguntar: se nada tivesse sido feito, qual teria sido o impacto sobre o nível das atividades econômicas e do emprego?

\section{CONSIDERAÇÕES FINAIS}

Este capítulo ressaltou a importância do Sistema Financeiro Internacional para a estabilidade e o desenvolvimento econômico de todos os países. Desde o final do século XIX, tivemos três formas de organização desse Sistema.

O primeiro denominava-se Sistema do Padrão Ouro, em que o ouro era a moeda internacional, e vigorou desde aproximadamente 1870 até o final da Primeira Guerra Mundial. Foi um sistema muito estável, mas a quantidade fixa de ouro também representava um obstáculo às atividades econômicas, impedindo que os governos pudessem estimular essas atividades através do gasto público.

O segundo foi o Sistema Financeiro de Bretton-Woods, um sistema financeiro regulado, como observamos, que praticamente evitou as crises financeiras e proporcionou um período de grande crescimento econômico, entre 1947 e 1973, para a quase totalidade dos países.

O terceiro é o Sistema Financeiro Globalizado Contemporâneo, que substituiu o sistema de Bretton-Woods, e se caracteriza pelas taxas de câmbio flutuantes e pela livre movimentação internacional de capitais. Esse sistema, justamente pelo seu caráter liberal, é muito propenso a provocar crises periódicas. Além da grande crise japonesa, houve inúmeras outras 
crises localizadas, até a grande crise americana de 2008, contudo, essas duas foram alvo deste estudo.

A bolha especulativa japonesa dos mercados de ações e de imóveis no Japão estourou em 1989, tendo como possíveis fatores a desregulamentação do sistema financeiro, da década de 1980, e, na sequência, o Acordo do Plaza, de 1985, assim como a condução da política monetária (FRAGA; STRACHMAN, 2013). Apesar dos efeitos negativos e do longo prazo gerados pela bolha especulativa, eles ficaram basicamente restritos à economia local (TORRES FILHO, 2015).

A crise americana de 2008, por sua vez, teve amplitude global, afetando inúmeros países (principalmente emergentes) envolvidos nas transações de crédito. Depois da crise, a economia do país sofreu um processo de reestruturação macroestrutural, principalmente no que diz respeito à liberação de crédito, diminuindo o ritmo de expansão de investimentos e limitando os empréstimos familiares. As empresas também passaram a acumular mais lucro e realizar investimentos com maior cautela diante do período recessivo pelo qual passaram, e a política de distribuição de renda (consumo de massas) adotada pelo governo americano após a segunda guerra mundial foi substituída pela política de incentivo às empresas e ao capital produtivo.

Assim, como principais diferenças entre a crise americana e a bolha especulativa japonesa, cabe destacar uma maior participação direta de pessoas físicas na economia e uma maior contração da demanda de serviço no caso do Japão, ao passo que nos EUA, a quebra do setor privado foi coberta pelo aumento do deficit dos cofres públicos nacionais, deixando as empresas americanas menos fragilizadas e com um endividamento menor que as do Japão, pois as consequências do episódio japonês ainda são sentidas atualmente (TORRES FILHO, 2015).

Por fim, em relação aos reflexos da crise norte-americana no Brasil, a economia mundial ainda não se recuperou dos seus impactos negativos, 
da mesma forma como a economia brasileira também continua sofrendo suas consequências.

O contexto apresentado pelas crises analisadas trouxe, ainda, uma lição para o desenvolvimento regional: a de que o ponto central para o desenvolvimento autossustentável são as forças produtivas e não o capital financeiro especulativo baseado em aplicações com altas taxas de juros. Em tempos de crise, o Estado procura implementar políticas anticíclicas para salvar a economia local. Segundo Carleial (2010, p. 29), o desenvolvimento regional brasileiro foi afetado pelo enxugamento do crédito internacional e pela redução do preço das commodities no mercado internacional, em função da diminuição das demandas e da volatilidade das firmas transacionais em território nacional.

Em síntese, as medidas anticíclicas adotadas pelos gestores locais brasileiros foram semelhantes às medidas adotadas pelos países desenvolvidos, como destaca Carleial (2010, p. 32): “foram medidas centradas em desonerações fiscais, manutenção/ampliação dos gastos de governo, ampliação dos recursos voltados para o seguro-desemprego e medidas especiais para apoiar setores estratégicos em dificuldades”.

\section{REFERÊNCIAS}

ALVES, W. V. Uma Breve História das Crises Econômicas. São Paulo: Fdigital LDP, 2012.

BAER, M. et al. Os desafios à reorganização de um padrão monetário internacional. Economia e Sociedade, Campinas, n. 4, p. 79-126, jun.1995. Disponível em: <http://www.eco.unicamp.br/docprod/downarq. php?id=425\&tp=a>. Acesso em: 20 jun. 2016.

BARROS, J. R. M. de. Crescer não é fácil: A crise, a economia mundial e o crescimento brasileiro. Rio de Janeiro: Elsevier, 2013.

BASTOS, C. P.; TEIXEIRA, L. Política econômica em tempos de crise:a reação do governo norte-americano à crise subprime. ANPEC, 2015. Disponível em: 
$<$ https://www.anpec.org.br/encontro/2015/submissao/files_I/i2-24a4778bc83 39fbb26fcce3efe026855.pdf>. Acesso em: 12 jun. 2016.

CARLEIAL, L. Crise econômica internacional e crise do trabalho: o que já podemos antecipar? In: MORETTO, A. et al. (Org.). Economia, desenvolvimento regional e mercado de trabalho do Brasil. Fortaleza: Instituto de Desenvolvimento do Trabalho, Banco do Nordeste do Brasil, Centro de Estudos Sindicais e de Economia do Trabalho, 2010. 364 p. Disponível em: <http://www.sineidt.org.br/Publicacoes/Livros/004_ Economia_Desenvolvimento_Regional_e_Mercado_de_Trabalho_do_Brasil. pdf $>$. Acesso em: 10 out. 2016.

CARVALHO, D. F. A crise financeira dos EUA e suas prováveis repercussões na economia global e na América Latina: uma abordagem pós-minskyana. In: III Encontro da Associação Keynesiana Brasileira. São Paulo, 2010. Disponível em: <http://www.ppge.ufrgs.br/akb/encontros/2010/05.pdf>. Acesso em: 13 jun. 2016.

DATHEIN, R. Sistema Monetário Internacional e Globalização Financeira nos Sessenta Anos de Bretton Woods. Revista da Sociedade Brasileira de Economia Política. Rio de Janeiro, no 16, p. 51-73, 2005. Disponível em: $<$ http://www.ppge.ufrgs.br/ricardodathein/publicacoes/sbep-junho2005.pdf >. Acesso em: 20 jun. 2016.

FRAGA, J. S.; STRACHMAN, E. Crise financeira: o caso japonês. Belo Horizonte: Nova Economia, 2013. Disponível em: <http://www.scielo.br/ scielo.php?script=sci_arttext\&pid=S0103-63512013000300002>. Acesso em: 20 jun. 2016.

GIL, A. C. Como elaborar projetos de pesquisa. 4. ed. [S.1]: Atlas, 2002.

INSTITUTO DE PESQUISA ECONÔMICA APLICADA (IPEADATA). Dados macroeconômicos e regionais. Disponível em: $<$ http://www.ipeadata. gov.br/>. Acesso em: 20 jun. 2016.

KINDLEBERGER, C. P.; ALIBER, R. Z. Da euforia ao pânico: uma história das crises financeiras. São Paulo: Gente, 2009.

LEAL, E. Capitalismo - Crise em 2007. Administradores: 2012. Disponível em: <http://www.administradores.com.br/artigos/economia-e-financas/ capitalismo-crise-em-2007/29796>. Acesso em: 14 jun. 2016. 
LEVI, M. L. Liberalização financeira, bolha especulativa e crise bancária no Japão.Revista Economia Política, v. 17, n. 1, 1997. Disponível em: <http:// www.rep.org.br/pdf/65-3.pdf> Acesso em: 11 out. 2016.

MARQUES, R. M.; ANDRADE, P. R. Brasil 2003-2015: balanço de uma experiência "popular". O olho da História, Salvador: n. 19, 20, 21, ago. 2015. Disponível em: <http://oolhodahistoria.ufba.br/brasil-2003-2015-balanco-deuma-experiencia-popular/>. Acesso em: 20 jun. 2016.

MUNHOZ, D. G. A fragilidade brasileira na crise pós-subprime. In: BISPO, C. R.; MUSSE, J. S.; VAZ, F. T.; MARTINS, F. J. (Org.). Crise Financeira Mundial: impactos sociais e no mercado de trabalho. Brasília: ANFIP, 2009. Disponível em: <http://dowbor.org/blog/wp-content/uploads/2012/06/102859970-CriseFinanceira-Mundial.pdf $>$. Acesso em: 20 jun. 2016.

OLIVEIRA, G. C. de; MAIA, G.; MARIANO, J. O Sistema de Bretton Woods e a Dinâmica do Sistema Monetário Internacional Contemporâneo. Pesquisa \& Debate, São Paulo, vol. 19, n. 2, p. 195-219, 2008. Disponível em: <http:// www.eco.unicamp.br/docprod/downarq.php?id=3288\&tp=a>. Acesso em: 20 jun. 2016.

PORTINHO, P. O mercado de ações em 25 episódios: história, estudos e crônicas sobre o mercado de ações. Rio Janeiro: Elsevier, 2009.

SOUSA, M. A Crise norte-americana do subprime - medindo o contágio para os BRICS. Dissertação (Mestrado em Economia) - Faculdade de Economia, f. 133, USP, São Paulo, 2011. Disponível em: <http://www.teses.usp. br/teses/disponiveis/12/12138/tde-19092011-144700/pt-br.php>. Acesso em: 20 jun. 2016.

TAVARES, M. da C. O Desafio Japonês. Folha de São Paulo. 1996. Disponível em: <http://www.eco.unicamp.br/artigos/tavares/artigo31.htm>. Acesso em: 15 jun. 2016.

TORRES FILHO, E. T. A crise da economia japonesa nos anos 90: impactos da bolha especulativa. Revista de Economia Política, v. 17, n. 1, 1997. Disponível em: <http://www.rep.org.br/pdf/65-1.pdf>. Acesso em: 15 jun. 2016.

. A crise do sistema financeiro globalizado contemporâneo.Revista de Economia Política, v. 34, n. 3, p. 433-450, 2014. Disponível em: <http://www. scielo.br/pdf/rep/v34n3/v34n3a05.pdf>. Acesso em: 15 jun. 2016. 
O estouro de bolhas especulativas recentes: os casos dos Estados Unidos e do Japão. Brasília: IPEA, 2015. Disponível em: <http://www.ipea.gov. br/portal/images/stories/PDFs/TDs/td_2096.pdf>. Acesso em: 16 jun. 2016.

O sistema Financeiro Globalizado Contemporâneo: Estrutura e Perspectivas. Brasília: IPEA, 2015a. Disponível em: <http://www.ipea.gov.br/ portal/images/stories/PDFs/TDs/td_2030.pdf>. Acesso em: 18 jun. 2016.

O Sistema Financeiro Globalizado Contemporâneo: Estrutura e Perspectivas. Textos para Discussão. Brasília: IPEA, 2015b. Disponível em: $<$ http://repositorio.ipea.gov.br/bitstream/11058/3366/2/td_2030_sumário_ executivo.pdf $>$. Acesso em: 18 jun. 2016. 